\title{
ENERGIA E MEIO AMBIENTE: O TRADE OFF ENTRE AS MATRIZES ENERGÉTICAS DE FONTES RENOVÁVEIS E NÃO RENOVÁVEIS NO BRASIL
}

\section{ENERGIA Y EL MEDIO AMBIENTE: EL TRADE OFF ENTRE LAS MATRICES ENERGÉTICAS DE FUENTES RENOVABLES Y NO RENOVABLES EN BRASIL}

\begin{abstract}
ENERGY AND THE ENVIRONMENT: THE TRADE OFF BETWEEN ENERGY MATRICES OF RENEWABLE AND NONRENEWABLE SOURCES IN BRAZIL
\end{abstract}

\author{
Andréa de SOUZA ${ }^{1}$ \\ Christian Luiz da SILVA ${ }^{2}$
}

\begin{abstract}
RESUMO: Este artigo procurou comparar três projetos que geram energia a partir de diferentes fontes, sendo duas renováveis (hidrelétrica e biomassa) e uma fonte não renovável (petróleo). Objetivou-se verificar os possíveis impactos socioambientais gerados por cada tipo de exploração e como se inter-relacionam na definição do planejamento energético e no processo de escolha da matriz energética brasileira. A metodologia empregada foi descritiva, com a utilização de fontes bibliográficas como relatórios, balanços, boletins oficiais do governo brasileiro, a Análise de Impacto Ambiental - AIE e o Relatório de Impacto Ambiental - RIMA para cada caso selecionado. Os resultados indicaram que a despeito da existência de fontes renováveis potenciais, as projeções de crescimento da economia brasileira apontam a necessidade de ações para a diversificação da matriz energética, bem como uma redefinição no padrão de exploração dos recursos existentes considerando os futuros cenários de exaustão.
\end{abstract}

Palavras-chave: Preservação Ambiental; Economia; Matriz Energética.

RESUMEN: La finalidad de este artículo ha sido comparar tres proyectos que generan energía a partir de distintas fuentes, dos renovables (hidroeléctrica y biomasa) y otra, no renovable (petróleo). El objetivo ha sido verificar los posibles impactos socio-ambientales generados por cada tipo de explotación, y como es su interrelación al definir la planificación energética durante el proceso que decide la matriz energética brasileña. La metodología empleada ha sido la descriptiva, utilizando fuentes bibliográficas, tales como informes, balances, boletines oficiales del gobierno brasileño, el Análisis del Impacto Ambiental - AIE y el Informe de Impacto Ambiental - RIMA, para cada caso seleccionado. Los resultados indicaron que pese a la existencia de fuentes renovables potenciales, las proyecciones de crecimiento de la economía

\footnotetext{
${ }^{1}$ Economista, Pesquisadora, Profa. e Doutoranda do Programa de Pós-Graduação em Tecnologia-PPGTE, da Universidade Tecnológica Federal do Paraná-UTFPR. asouza70@gmail.com.br

${ }^{2}$ Prof. Dr., Pesquisador, Departamento de Gestão e Economia, Economista, PPGTE/UTFPR. christianlsilva@uol.com.br
} 
brasileña apuntan la necesidad de acciones para la diversificación de la matriz energética, además de la redefinición del modelo de explotación de los recursos existentes, llevando en cuenta los futuros escenarios de agotamiento.

Palabras-clave: Preservación ambiental; Economía; Matriz Energética.

\begin{abstract}
The purpose of this paper was to compare three projects that generate energy from different sources, two renewable (hydroelectric, and biomass) and other non-renewable (oil). The objective was to verify the eventual environmental impacts generated by each type of energy exploration, and how is their relationship when defining the energy planning during the process that decides the Brazilian energy matrix. For each selected case, the descriptive methodology has been used, with literature sources such as reports, balance sheets, the Brazilian government newsletters, Environmental Impact Analysis - IEA and the Environmental Impact Report - RIMA. The results indicated that despite the existence of potential renewable sources, the projected growth of the Brazilian economy indicates the need of actions to diversify the energy matrix, as well as redefine the model of exploitation of existing resources, taking into account future scenarios of exhaustion.
\end{abstract}

Key-words: Environmental Protection; Economy; Energy Matrix.

\title{
INTRODUÇÃO
}

A matriz energética brasileira até a década de 1970 era dependente de apenas duas fontes de energia: o petróleo e a lenha, que juntas respondiam por $78 \%$ do consumo. O Brasil aparece como o quinto país que mais investe em energia renovável, de acordo com Relatório da Conferência das Nações Unidas para o Comércio e Desenvolvimento (2011), mas atua praticamente em setores já consolidados como o biocombustível e as hidrelétricas.

A despeito da perspectiva econômica favorável ao país, há de se considerar que as formas de exploração dos recursos naturais provocam impactos ambientais que podem demandar uma redefinição da atual matriz energética. Acidentes com derramamento de petróleo, o desmatamento ilegal de florestas e as críticas em torno da construção da terceira maior hidrelétrica do mundo, Belo Monte, reforçam a necessidade de se rever os custos do crescimento brasileiro e que modelo de desenvolvimento energético o país pretende adotar no futuro.

Este artigo objetiva comparar três diferentes empreendimentos de geração de energia sob a perspectiva dos impactos ambientais, econômicos e sociais a partir dos seus documentos oficiais de licenciamento. A estrutura do artigo se propõe a discutir o papel do planejamento energético, a composição da atual matriz energética brasileira e a resposta aos impactos 
ambientais ocasionados pela exploração das principais fontes de energia no Brasil. Apresenta a metodologia empregada, faz um descritivo dos projetos estudados na pesquisa, sintetiza os principais resultados e por fim na seção apresenta as considerações finais.

\section{Planejamento Energético Brasileiro: escolhas entre as fontes da matriz energética e os respectivos impactos ambientais}

No setor energético, a importância do planejamento foi comprovada a partir do primeiro choque do petróleo na década de 1970. O planejamento considerava basicamente o setor de eletricidade, carvão e petróleo, mas negligenciava a utilização de fontes renováveis. De acordo com a EPE (2005, p.16) "a abordagem tradicional do planejamento considerava basicamente apenas opções de oferta e mesmo assim essas eram limitadas por algumas tecnologias dominantes numa perspectiva de análise de custo-benefício".

Como solução de curto prazo para o problema da crise do petróleo, o governo brasileiro visualizou nas hidrelétricas a continuidade de abastecimento de energia elétrica para sustentar o crescimento e expansão da economia naquele momento. O que se conseguiu com essa política não foi mais que "uma coleção de planos desagregados de investimentos no setor elétrico com desvantagens" [...] entre as quais "a ausência de mecanismos capazes de tratar as interfaces entre as questões ambientais e energéticas" (EPE, 2005 p.13).

As características técnicas, econômicas, o escopo e a complexidade dos aspectos envolvidos no funcionamento da indústria de energia explicam a importância do planejamento do setor energético. Há de se considerar ainda os diferentes atores envolvidos tanto do lado da oferta como da demanda, em especial os formuladores de política e as agências reguladoras, estas últimas com expressivo poder de influência sobre as variáveis do sistema (EPE, 2005).

A partir da década de 1980, com o fortalecimento da dimensão ambiental, as discussões em torno das mudanças climáticas e o aumento das preocupações sociais, repercutiu sobre o planejamento energético o conceito de Planejamento Integrado de Recursos - PIR. De acordo com Reis et al. (2012, p.344) "o planejamento integrado pode ser entendido como o processo que examina todas as opções possíveis e factíveis, no tempo e no espaço, para responder a questão da energia (no sentido do bem-estar), selecionando as melhores alternativas". O autor apresenta o PIR como um ferramental de análise que posiciona conjuntamente as expectativas de opções em suprimento e demanda e destaca que uma das suas principais características é a a abordagem abrangente, completa e sistêmica, o que permite "a opção de custo mínimo com melhoria na proteção do meio ambiente; conservação na sua acepção mais ampla e, ainda, 
melhoramentos no transporte e na localização" (REIS, 2012 p.343.

Contudo, a despeito das vantagens aparentes do PIR, em diversos países ainda persistem barreiras para aceitação deste modelo. No Brasil, avanços tem sido alcançados nesse sentido mas ainda persistem a dificuldade de introdução de tecnologias renováveis, a falta de informação, barreiras legais e institucionais. Destaca-se o potencial em conservação e eficiência energética, contudo, faltam recursos para melhor desenvolver essas políticas no setor público brasileiro (EPE, 2005).

A matriz energética brasileira é composta por $44,1 \%$ dos recursos de fonte renovável enquanto no mundo essa participação é de apenas 13,3\% (EPE, 2012 p.2). Esta composição apresenta-se como uma ameaça e uma oportunidade, haja vista que a maioria dos países desenvolvidos e em desenvolvimento, assumiu o compromisso da promoção do crescimento sócio e ambiental em níveis sustentáveis.

No caso brasileiro destaca-se a importância do mercado de etanol. O Brasil e a Índia são os maiores produtores mundiais de cana-de-açúcar e isoladamente o Brasil é considerado o maior exportador de açúcar, 25,3 milhões de toneladas em 2011 (Anuário Estatístico da Agroenergia, 2010). Dados do BEN (2011) apontaram que em 2010 houve aumento de 11,6\% na produção nacional de açúcar e um acréscimo de $7,1 \%$ na produção de etanol. Adicionalmente o bagaço da cana-de-açúcar pode ser queimado pelas próprias refinarias para a produção de eletricidade. No ano de 2010, do total de $145.51910^{3}$ t de consumo final de bagaço da cana, $42 \%$ destinou-se a produção de energia para suprir as usinas alcooleiras revelando a importância desse subproduto como alternativo em energia elétrica (BEN, 2010 p.46).

No que diz respeito à geração hidráulica, as dez maiores hidrelétricas brasileiras respondem atualmente por $28,9 \%$ da capacidade instalada brasileira, que juntas chegam a 32,9 mil Megawatts (MW) em potência outorgada. A capacidade total do país até o dia 28 de junho de 2012 era 118.342.458 kW de potência oriunda das hidrelétricas, termelétricas, fontes eólicas, fotovoltaica e maremotriz (BIG/ANEEL, 2012).

No ano de 2010, a energia não renovável representou 52,5\% do total da produção de energia primária, das quais, $42 \%$ foi efetivamente produção de petróleo. Nas Américas, o Brasil é a segunda maior reserva confirmada de petróleo. A produção deste energético em 2010 chegou a $119.59510^{3} \mathrm{~m}^{3}$ um aumento de 5\% em relação ao ano de 2009 (BEN, 2011 p.40). Segundo a PETROBRÁS “a demanda de investimentos para o pré-sal deverá superar US\$ 400 bilhões em materiais, equipamentos, sistemas e serviços, até 2020" (ANP, 2012). Espera-se que 
a exploração do pré-sal impulsione investimentos em pesquisa e desenvolvimento (P\&D), infraestrutura e capacitação de pessoal, o que ressalta o papel desenvolvimentista desta atividade no contexto da expansão e posicionamento do Brasil entre as maiores economias do mundo.

O Ministério de Minas e Energia - MME, é o órgão responsável pelo planejamento energético nacional e a execução das políticas estabelecidas pelo Conselho Nacional de Política Energética - CNPE (PDEE, 2020). Entenda-se por matriz energética "o fluxo energético relativo ao conjunto de fontes energéticas empregadas no processo produtivo de um país" (NOGUEIRA PINTO, 1990, p.74).

De acordo com Plano Decenal de Expansão de Energia - PDEE 2020, o conceito de sustentabilidade guiou os estudos socioambientais focando nas alternativas de maior sustentabilidade e considerando as atuais discussões e negociações internacionais sobre as mudanças do clima. Em âmbito nacional, a questão climática foi reforçada pela promulgação da lei 12.187/09, onde foi estabelecida de forma voluntária, a nova meta de redução das emissões de gases de efeito estufa (GEE) em 38,9\% num cenário de referência para 2020.

Com a possibilidade de ampliação da oferta de gás natural associado à produção do PréSal, a expansão da geração termelétrica a gás poderá vir a ocupar um maior espaço na matriz energética brasileira, pela dificuldade na obtenção de licenciamento ambiental de usinas hidrelétricas e de linhas de transmissão. O PDEE 2020 não contemplou essa forma de expansão para o ciclo atual, mas sinalizou que poderá considerá-lo nos próximos ciclos decenais.

O primeiro registro de fundamentos de Avaliação de Impactos Ambientais (AIA) ocorreu nos Estados Unidos em 1969, quando o Congresso americano aprovou a National Environmental Policy of Act - NEPA (ROCHA, et al. 2005). No Brasil a primeira referência legal ao estudo de impacto ambiental é a Lei № 6.803 de 1980 ainda no regime militar (PLANALTO, 2012). Segundo Machado (1995), o Estudo de Impacto Ambiental - EIA abrange o levantamento da literatura científica e legal, trabalhos de campo, análises de laboratórios e a própria redação do documento em sua versão final. O Relatório de Impacto Ambiental - RIMA "refletirá as conclusões do Estudo de Impacto Ambiental" (art. $9^{\circ}$ da Resolução 001/86 do Conama). O EIA é realizado anteriormente ao RIMA, sendo a base para elaboração deste último, constituindo-se, portanto, em atividades interdependentes.

O Artigo $1^{\circ}$ da Resolução n. ${ }^{\circ}$ 001/86 define Impacto Ambiental como "qualquer alteração das propriedades físicas, químicas, biológicas do meio ambiente, causada por qualquer forma de matéria ou energia resultante das atividades humanas que afetem diretamente ou 
indiretamente" (MMA, 2012 p.1). Deve ser considerada a segurança e o bem estar da população, as atividades sociais e econômicas, a biota, as condições estéticas e sanitárias ambientais e por fim a qualidade dos recursos ambientais (MMA, 2012). As atividades técnicas mínimas que o estudo de impacto ambiental deve contemplar estão descritas no Artigo $6^{\circ}$ e $7^{\circ}$ da Resolução n. ${ }^{\circ}$ 001/86. O Artigo $9^{\circ}$ da mesma resolução dispõe sobre as conclusões do Relatório de Impacto Ambiental - RIMA.

\section{METODOLOGIA}

A metodologia de pesquisa adotada foi descritiva expondo características de determinada população e seu padrão de comportamento. Segundo Vergara (2007 p.47) a pesquisa descritiva também pode estabelecer correlações entre variáveis e definir sua natureza. Quanto aos meios, utilizou-se a pesquisa em fontes bibliográficas como relatórios, balanços e boletins oficiais do governo brasileiro, Análise de Impacto Ambiental - AIE e Relatório de Impacto Ambiental RIMA para cada caso selecionado, bem como textos teóricos de outros pesquisadores.

A análise concentrou-se nas principais fontes energéticas em discussão atualmente no Brasil: o petróleo, a energia hidráulica, a biomassa a partir da cana-de-açúcar e os possíveis impactos do potencial de exploração do pré-sal. Foram abordados por este estudo, os principais impactos esperados pela implantação da Usina Hidrelétrica de Belo Monte, atualmente em fase de instalação do canteiro de obras, exploração de petróleo (camada de pré-sal da bacia de Santos em fase de operação), e o projeto de implantação de uma usina de cana de açúcar, Unidade industrial Brazil Flex Energy, que aguarda parecer de seu EIA/RIMA. Todos esses projetos foram detalhados no item 5 desse trabalho.

Os impactos foram classificados conforme descrito em seus respectivos EIA/RIMA e se restringiram a análise dos documentos de licenciamento ambiental de cada empreendimento. Cabe esclarecer que os estudos foram desenvolvidos em diferentes tempos e por empresas contratadas pelos empreendedores. A estrutura dos relatórios apresenta diferenças de nomenclaturas e consideram particularidades específicas de cada projeto, mas todos os estudos devem cumprir elementos mínimos, conforme estabelecido na segunda seção.

O objetivo de se tomar os documentos de EIA/RIMA de cada projeto como fonte de estudo foi indicar e exemplificar possíveis impactos e variáveis de decisões diferentes da explicitamente econômica, mas que, obviamente, não se restringe aos levantados pelo estudo, 
dado que cada situação de análise provocará distintos impactos. Observe-se que a escolha destes estudos deveu-se, também, a disponibilidade e facilidade de acesso da informação com maior número de detalhes possíveis em cada segmento de análise. A análise desses documentos permitiu a construção de um quadro referencial com variáveis envolvidas na tomada de decisão de cada alternativa cujos detalhes constam nos quadros 9 e 10.

Os estudos de EIA/RIMA de Belo Monte utilizado nessa pesquisa é de 2009, última versão disponibilizada pela ELETROBRÁS. A responsabilidade técnica foi da empresa Leme Engenharia que reuniu todas as informações em 36 volumes, respeitando o Termo de Referência (TR) emitido pelo IBAMA em dezembro de 2007 para a elaboração deste EIA/RIMA (ELETROBRÁS, 2009). Este documento traz orientações sobre o empreendimento, explica como se darão os efeitos positivos e negativos resultantes do projeto, as ações ambientais que estão sendo propostas bem como as mudanças já realizadas feitas no projeto de engenharia da UHE Belo Monte.

Os critérios para identificação e avaliação dos impactos e suas interações com o ambiente, do projeto da Bacia de Santos obedecem ao disposto nos manuais básicos para elaboração de documentos de licenciamento. O documento utilizado nesse estudo foi o RIMA Relatório de Impacto Ambiental - PETROBRÁS, Revisão 2, Março de 2011, elaborado pela empresa ICF Internacional / ICF Consultoria do Brasil. Maiores detalhes sobre a metodologia empregada no relatório da companhia, podem ser encontrados na Seção 9 Impactos Ambientais Relacionados à Atividade, p. 43 a 45 do referido documento. Este empreendimento encontra-se em fase de exploração.

A empresa Brazil Flex Energy apresentou seu EIA/RIMA para subsidiar o corpo técnico da Companhia Ambiental do Estado de São Paulo na emissão da licença prévia da implantação do projeto de implantação de uma usina de cana-de-açúcar Tais estudos foram elaborados a partir das diretrizes do Termo de Referência - Parecer Técnico 81.690/09/TA, e fundamentaram-se nas diretrizes: Resolução CONAMA n 001/86, Resolução CONAMA 237/97, Resolução SMA 42/06, Resoluções SMA 88/08 e Zoneamento Agroambiental para o setor sucroalcooleiro no Estado de São Paulo, regulamentado pela Resolução SMA-SAA n. ${ }^{\circ}$ 06/2009 (BRAZIL FLEX ENERGY, 2011 p.1). A empresa responsável pelo EIA/RIMA foi a PROJEC Projetos e Consultoria Ltda. 


\section{DESCRIÇÃO DOS PROJETOS ANALISADOS NA PESQUISA}

Esta seção resume as principais características técnicas de cada projeto para o qual foram utilizados os respectivos EIA/RIMA de referência para esse estudo.

\section{Usina Hidrelétrica de Belo Monte}

A UHE Belo Monte será construída no rio Xingu, nos municípios de Altamira e Vitória do Xingu, Estado do Pará. De acordo com a ELETROBRÁS, em 1975 o governo brasileiro iniciou os primeiros estudos de Aproveitamento Hidrelétrico (AHE) da bacia do rio Xingu, mas foi somente em Julho de 2008, que a Agência Nacional de Energia Elétrica - ANEEL aprovou a atualização do inventário hidrelétrico e a UHE Belo Monte, foi considerada viável (NORTE ENERGIA; ELETROBRAS, 2012). O licenciamento ambiental teve início em 2006 e a Licença Prévia (LP) foi emitida em fevereiro de 2010.

A construção da usina é responsabilidade da Norte Energia (NESA), consórcio vencedor do leilão realizado em abril de 2010, composto pelo Grupo Eletrobrás (participação combinada de 49,9\%) e um grupo de empresas brasileiras privadas (EPE, 2011 p.1). O Quadro 1 apresenta os principais dados técnicos relacionados ao empreendimento da UHE Belo Monte.

Quadro 1 - Macro dados técnicos da Usina Hidrelétrica de Belo Monte

\begin{tabular}{|c|l|}
\hline INDICADOR & \multicolumn{1}{|c|}{ DESCRIÇÃO } \\
\hline Capacidade Instalada & $11.233,1 \mathrm{MW}$ \\
\hline Garantia Física & $\begin{array}{l}4.571 \mathrm{MWmédios} \text { (fator de capacidade de 41\%); vazão média de 8.000 } \\
\text { m3/s, queda de cerca de 90 m }\end{array}$ \\
\hline Usina a Fio D’água & $\begin{array}{l}\text { Não altera a hidrologia do rio Xingu devido a operação do reservatório } \\
\text { com nível constante; vazões mínimas serão mantidas na volta grande do } \\
\text { Xingu. }\end{array}$ \\
\hline Área Inundada & $\begin{array}{l}516 \mathrm{~km} 2 \text { dos quais 228 km2 corresponde ao leito natural do rio, } \\
\text { representando 0,04 km2/MW, 12 vezes inferior à média nacional de 0,49 } \\
\text { km2/MW, como resultado da revisão do projeto da usina. }\end{array}$ \\
\hline Conexão da Usina & $\begin{array}{l}\text { Na linha de transmissão Tucuruí/Manaus (dois circuitos de 500 kV para } \\
\text { o Nordeste e dois circuitos de 500 kV para Manaus, já existentes quando } \\
\text { do início da operação de Belo Monte). }\end{array}$ \\
\hline $\begin{array}{c}\text { Integração Energética da } \\
\text { Usina no SIN/Sistema } \\
\text { Interligado Nacional }\end{array}$ & $\begin{array}{l}\text { A geração média anual de energia da usina será plenamente } \\
\text { disponibilizada para o SIN. A geração de Belo Monte é sazonal (elevada } \\
\text { nos meses de cheia e reduzida nos meses de seca do rio), sendo } \\
\text { compensada pela operação conjugada dos diversos reservatórios do SIN. } \\
\text { Consideradas as fontes biomassa e eólica. }\end{array}$ \\
\hline
\end{tabular}

FONTE: Adaptado de VENTURA FILHO (2011). 


\section{Polo Pré-Sal Bacia de Santos (SP)}

A Petrobrás iniciou suas atividades na Bacia de Santos em maio de 2009, quando registrou a primeira produção de óleo no pré-sal a partir da implantação de um Teste de Longa Duração na área de Tupi (BALANÇO PAC 2010). Esta área está localizada na sua porção central, em frente aos estados de São Paulo e Rio de Janeiro. A camada de sal funciona como uma rocha selante retendo o petróleo no interior destes reservatórios e funcionando como uma espécie de barreira [...] "que impede a migração de petróleo e gás natural das rochas reservatório, favorecendo a sua acumulação” (RIMA PETROBRÁS, 2011 p.5).

Os Quadros 2 e 3 apresentam a descrição sintética das atividades deste projeto e outros detalhes técnicos podem ser consultados na p.6 do documento original. A Petrobrás estimou que em 2011 foi gerado cerca 1.800 postos de trabalhos relacionados aos TDL's, Pilotos e DP no Polo Pré-Sal (Bacia de Santos), dos quais a maior parte será absorvida do quadro de funcionários da companhia. A empresa espera estimular a abertura de novos postos de serviços indiretos nos setores de alimentação, aluguel, transporte, aquisição de bens dentre outros (RIMA PETROBRÁS, 2011 p.43).

Quadro 2 - Descrição geral das atividades do Projeto da Bacia de Santos

\begin{tabular}{|c|c|c|}
\hline ATIVIDADE & DESCRIÇÃ̃O & $\begin{array}{l}\text { PREVISÃO INICIO } \\
\text { DAS ATIVIDADES }^{1}\end{array}$ \\
\hline $\begin{array}{l}\text { Testes de Longa } \\
\text { Duração }\end{array}$ & $\begin{array}{l}\text { Distribuídos em } 7 \text { áreas e } 14 \text { TDLs, devem testar a } \\
\text { capacidade de produção dos reservatórios e avaliar } \\
\text { o comportamento da produção. }\end{array}$ & 2012 a 2012 (TDL’s) \\
\hline Pilotos de Produção & $\begin{array}{l}\text { Objetivam verificar o comportamento da injeção de } \\
\text { água e gás nos reservatórios. Área de Guará (Piloto } \\
\text { Guará) e Tupi (Piloto Tupi e DP de Iracema) }\end{array}$ & $\begin{array}{c}2012 \text { (Guará) } \\
2013 \text { (Tupi NE) } \\
\text { Duracão } \approx 27 \text { anos }\end{array}$ \\
\hline $\begin{array}{l}\text { Desenvolvimento da } \\
\text { Produção }\end{array}$ & $\begin{array}{l}\text { Desenvolver a produção e o escoamento de óleo e } \\
\text { gás na área de Iracema na Bacia de Santos. }\end{array}$ & $\begin{array}{c}2014 \\
\text { Duração } \approx 27 \text { anos }\end{array}$ \\
\hline
\end{tabular}

FONTE: Adaptado de RIMA PETROBRÁS (2011).

${ }^{1}$ Estas datas representam a expectativa da PETROBRÁS.

Quadro 3 - Previsões para as atividades do projeto da Bacia de Santos

\begin{tabular}{|c|c|c|}
\hline ATIVIDADE & $\begin{array}{l}\text { PRODUÇÃO PREVISTA } \\
\text { (barril de petróleo por dia) }\end{array}$ & $\begin{array}{c}\text { (\% ) PETRÓLEO } \\
\text { PRODUZIDO NO } \\
\text { BRASIL }\end{array}$ \\
\hline Cada um dos 14 TDL's & $14.000(\mathrm{bpd})$ & $1,39 \%$ \\
\hline $\begin{array}{l}\text { Vazão de produção esperada para o } \\
\text { Piloto Guará e Piloto de Tupi NE }\end{array}$ & $\begin{array}{c}\approx 120.000 \mathrm{bpd} \\
\approx 3,2 \mathrm{MM} \mathrm{m} / \mathrm{d}^{10} \mathrm{de} \text { gás }\end{array}$ & $\begin{array}{l}\text { Cada piloto } \\
5,94 \%\end{array}$ \\
\hline Desenvolvimento da Produção & $\begin{array}{c}\approx 125.000 \text { bpd e } 6 \mathrm{MM} \\
\mathrm{m}^{3} / \mathrm{d}^{10} \text { de gás }\end{array}$ & $6,19 \%$ \\
\hline
\end{tabular}

FONTE: Adaptado de RIMA PETROBRÁS (2011). 


\section{Unidade Industrial Brasil Flex Energy}

A Unidade Industrial Brasil Flex Energy, será instalada na zona rural do município de Rosana (SP). Essa unidade terá como atividades a fabricação de etanol, açúcar, geração de energia elétrica e produção de cana-de-açúcar: matéria-prima (RIMA BRASIL FLEX ENERGY, 2010). A implantação do empreendimento está estimada em 18 meses a partir de outubro de 2012. O planejamento prevê o início das atividades no ano/safra 2014-15 e deverá alcançar a capacidade máxima de moagem de cana-de-açúcar a partir do sexto ano safra 2019/20. O Quadro 4 relaciona os principais parâmetros do projeto tais como investimentos, capacidade de processamento, produção de energia e outras informações gerais.

Quadro 4 - Macro Dados Técnicos da Unidade Fabril Brazil Flex Energy

\begin{tabular}{|c|l|}
\hline INDICADOR & \multicolumn{1}{|c|}{ DESCRIÇÃO } \\
\hline Investimentos previstos & $\mathrm{R} \$ 120.000,00$ (máquinas e equipamentos). \\
\hline $\begin{array}{c}\text { Capacidade de processamento } \\
\text { efetiva }\end{array}$ & $\begin{array}{l}3 \text { milhões de ton de cana-de-açúcar; 124,5 mil m³ de etanol } \\
\text { e } 105.0 \text { mil ton de açúcar/safra. }\end{array}$ \\
\hline Produção de energia elétrica & $\begin{array}{l}295,5 \text { mil MW de energia elétrica, dos quais 31\% destinam-se a } \\
\text { consumo próprio e 69\% à comercialização. }\end{array}$ \\
\hline Subprodutos do processamento & $\begin{array}{l}\text { Bagaço (queimados nas caldeiras) } \rightarrow \text { energia elétrica. } \\
\text { Vinhaça, torta-de-filtro, fuligem e cinza - fontes de fertilizantes. } \\
\text { Óleo fusível: comercializado com indústrias químicas. }\end{array}$ \\
\hline Área de cultivo & 23.185.000 hec, produção de 2 milhões de ton de cana-de-açúcar. \\
\hline $\begin{array}{c}\text { Unidades de conservação } \\
\text { diagnosticadas }\end{array}$ & $\begin{array}{l}\text { Estação Ecológica Mico-Leão-Preto, Área de Proteção Ambiental } \\
\text { das Ilhas e Várzeas do Rio Paraná, Parque Estadual do Morro do } \\
\text { Diabo. }\end{array}$ \\
\hline $\begin{array}{c}\text { Demanda hídrica do } \\
\text { Parque Industrial }\end{array}$ & $360 \mathrm{~m}^{3} / 20 \mathrm{~h} /$ dia = Aquífero Guarani. \\
\hline Uso da água no processo & Manutenção do consumo em $0,44 \mathrm{~m}^{3} /$ tonelada/cana moída. \\
\hline
\end{tabular}
FONTE: Adaptado de RIMA BRAZIL FLEX ENERGY (2011 p.5-17).

Para responder ao grau de exigência dos mercados globais, a gestão da produção agrícola e gestão ambiental serão fundamentais para o alcance das metas estratégicas da empresa nos mercados nacional e internacional. Planos e Programas para mitigar ou minimizar os impactos relacionados no EIA/RIMA devem assegurar o alcance de resultados positivos para os stakeholders. 


\section{Resultados dos principais impactos ambientais apontados pelos EIA/RIMA de cada projeto}

Esta seção trata dos principais impactos ambientais apontados pelos EIA/RIMA de cada projeto. Observe-se que para o caso da UHE Belo Monte o projeto encontra-se em fase inicial de instalação do canteiro de obras, as atividades da Bacia de Santos já estão em estágio avançado de exploração e o projeto da Brasil Flex Energy encontra-se em fase de licenciamento pelos órgãos competentes.

\section{Usina Hidrelétrica de Belo Monte}

Relatórios da década de 1980 e 1990 para a UHE Belo Monte previam maiores extensões de área para o reservatório de água, entretanto, ao longo da fase de estudos, se concluiu que tamanha extensão era inviável e altamente impactante ao meio ambiente, de forma que a área alagada do reservatório passou de $1.225 \mathrm{~km}^{2}$ para $516 \mathrm{~km}^{2}$. Outro ponto ressaltado é a relação área-capacidade de $0,05 \mathrm{~km}^{2} / \mathrm{MW}$, inferior a média das usinas brasileiras tais como Tucuruí $(0,29)$ e Itaipu (0,10). A média nacional é de 0,49 km²/MW instalado (EPE, 2011 p.2).

A Figura 1 relaciona os principais impactos esperados durante o desenvolvimento das atividades, uma estimativa de tempo de cada impacto, e em que fase do projeto ocorrerá (RIMA UHE BELO MONTE, 2009 p.137). O Projeto Básico Ambiental prevê o estabelecimento de 14 Planos para mitigar, corrigir e/ou minimizar os impactos no meio físico e socioambiental; 54 distribuídos em 14 para atender o meio físico, 11 o meio biótico, e 29 programas voltados a impactos socioeconômicos, e um total de 86 Projetos, dos quais 44 são para a área socioeconômica, 30 para o meio biótico e 12 destinados ao meio físico.

A construção da UEH Belo Monte é um projeto polêmico e objeto de muitas críticas, especialmente por parte de ambientalistas e dos envolvidos diretamente pelos impactos da obra, pois envolve o dilema econômico entre crescimento e preservação socioambiental. Até junho de 2011 a Norte Energia havia investido cerca de R \$ 70 milhões em ações socioambientais na área de influência da usina. Este investimento vem sendo realizado exclusivamente pelos sócios do empreendimento (NORTE ENERGIA, p. 16-17, 2011) com o objetivo de atender as demandas socioambientais.

Considera-se um importante custo de oportunidade da não realização desta obra, um provável cenário com falta de energia para sustentar o crescimento da economia brasileira. No ano de 2011 enquanto o PIB cresceu 2,7\% a oferta interna de energia cresceu apenas 1,3\% em 
relação a 2010. Atualmente são confirmados os resultados positivos em eficiência energética (EPE, 2012), entretanto, cabe observar que apenas ganhos dessa natureza são incapazes de sustentar um crescimento energointensivo como no caso brasileiro. O Quadro 6 apresenta o comparativo entre UHE Belo Monte e outras fontes renováveis.

Quadro 5 - Comparativo entre tecnologias de geração de energia

\begin{tabular}{|c|c|c|c|c|c|c|c|c|}
\hline & Unidade & $\begin{array}{c}\text { Belo } \\
\text { Monte }\end{array}$ & РCH & Eólica & Biomassa & Solar & $\begin{array}{c}\text { Gás } \\
\text { Natural }\end{array}$ & Nuclear \\
\hline Custo (*) & $\mathrm{R} \$ / \mathrm{MWh}$ & 77,97 & 135 & 148 & 153 & 500 & 143 & 150 \\
\hline $\begin{array}{l}\text { Capacidade } \\
\text { Instalada }\end{array}$ & MW & 11.233 & $8.310^{(1)}$ & $15.240^{(2)}$ & 9.522 & $28.570^{(3)}$ & 6.530 & 5.078 \\
\hline $\begin{array}{c}\text { Fator de } \\
\text { Capacidade }\end{array}$ & $\%$ & 41 & 55 & 30 & 48 & 16 & 70 & 90 \\
\hline $\begin{array}{c}\text { Custo de } \\
\text { Instalação }\end{array}$ & $\mathrm{R} \$ / \mathrm{kW}$ & 1.700 & $\begin{array}{l}5.000 \mathrm{a} \\
6.000\end{array}$ & $\begin{array}{l}3.660 \mathrm{a} \\
4.500\end{array}$ & $\begin{array}{l}2.170 \mathrm{a} \\
2.740\end{array}$ & $\begin{array}{c}12.600 \mathrm{a} \\
18.300\end{array}$ & $\begin{array}{c}1.280 \mathrm{a} \\
1.640\end{array}$ & 6.400 \\
\hline $\begin{array}{l}\text { Custo total } \\
\text { Instalação }\end{array}$ & $\mathrm{Bi} / \mathrm{R} \$$ & 20 & 41 a 50 & 47 a 84 & 21 a 26 & $\begin{array}{c}360 \mathrm{a} \\
523\end{array}$ & 8,4 a 10,7 & 32 \\
\hline Área & $\mathrm{Km}^{2}$ & 516 & $\begin{array}{l}830 \mathrm{a} \\
1.660\end{array}$ & $\begin{array}{c}2.180 \mathrm{a} \\
3.050\end{array}$ & 80.000 & 280 & - & - \\
\hline $\begin{array}{l}\text { Emissões } \\
\text { atuais }\end{array}$ & $\mathrm{tCO}_{2} / \mathrm{ano}$ & - & - & - & - & - & 16.156 .800 & - \\
\hline
\end{tabular}

FONTE: VENTURA FILHO (2011)

(1) 277 a 554 usinas; ${ }^{(2)} 10.160$ turbinas de $1,5 \mathrm{MW} ;{ }^{(3)} 140.000 .000$ de painéis solares de 220W.

Observe-se que a substituição da geração da usina de Belo Monte por outras fontes renováveis (biomassa e eólica) poderia encarecer o custo/preço da energia para o mercado regulado; além disto, possivelmente seria necessário adicionar geração de energia térmica e/ou derivados de petróleo a custos mais elevados para garantir a energia firme.

Como dado complementar, estima-se que o custo de uma usina térmica a gás natural, ciclo combinado, é de $\mathrm{R} \$ 24.125 .040 .000,00$, oito vezes superior a uma UHE Belo Monte (TOLMASQUIM, 2012). Vale destacar os investimentos totais previstos para a geração de energia até 2030 para as diferentes fontes: petróleo e derivados US\$ 395 bilhões (47\% anual); gás natural US\$ 95 bilhões (12\% anual); cana-de-açúcar US\$ 30 bilhões (4\% anual) e em eletricidade US\$ 286 bilhões (35\% anuais). Tais investimentos poderão chegar a 2,2\% do PIB na média anual (TOLMASQUIM et al. 2007, p. 68). Fica evidente a tendência de se manterem os investimentos na fonte hidráulica que se mostra a mais competitiva entre as energias comparadas. 
Figura 1 - Principais impactos sócio ambientais Usina de Belo Monte.

IMPACTO

Geração de expectativas (futuro da população local/região)

Geração de Expectativas na População Indigena

Aumento da população e da ocupação desordenada do solo

Aumento da Pressão sobre as Terras e Áreas Indígenas

Aumento das Necessidades: mercadorias, serviços, Oferta trabalho e maior movimentação Economia

Perda de Imóveis e Benfeitorias com Transferência da População na Área Rural/Perda Atividades Produtivas

Perda de Imóveis e Benfeitorias com Transferência da População na Área Urbana/ Perda Atividades Produtivas

Melhorias dos acessos

Mudanças na paisagem (causadas pela instalação da infra-estrutura de apoio e das obras principais)

Perda de Vegetação e de Ambientes Naturais, Mudanças na Fauna ${ }^{(a)}$

Aumento do Barulho e da Poeira com Incômodo da População e da Fauna ${ }^{(a)}$

Mudanças no Escoamento, Qualidade Água e Igarapés do Trecho do Reservatório dos Canais,

com mudanças nos Peixes

Alterações nas Condições de Acesso pelo Rio Xingu das Comunidades Indígenas à Altamira (b)

Alteração da Qualidade da Água do rio Xingu próximo ao Sítio Pimental e Perda de Fonte de

e de sustento das populações Indígenas

Danos ao Patrimônio Arqueológico

Interrupção Temporária do Escoamento da Água no Canal da Margem Esquerda do Xingu, no Trecho

entre a barragem principal e o núcleo de Referência Rural São Pedro 7 MESES

Perda de Postos de Trabalho e Renda (causada pela desmobilização de mão de obra)

Retirada de Vegetação, Perda de Ambientes Naturais e Recursos Extrativistas ${ }^{(c)}$

Mudanças na Paisagem e Perda de Praias e Áreas de Lazer ${ }^{(c)}$

Inundação Permanente dos Abrigos da Gravura e Assurini e Danos ao Patrimônio Arqueológico

Perda de Jazidas de Argila Devido à Formação do Reservatório do Xingu

Mudanças nas Espécies de Peixes e no Tipo de Pesca ${ }^{\text {(c) }}$

Alteração na Qualidade das Águas dos Igarapés de Altamira e no Reservatório dos Canais ${ }^{\circ}$

Interupção de Acessos Viários pela Formação do Reservatório dos Canais

Interrupção de Acessos na Cidade de Altamira (causada pela formação do Reservatório do Xingu)

Mudanças nas Condições de Navegação ${ }^{(c)}$

Aumento da Quantidade de Energia a ser Disponibilizada para o SIN

Dinamização da Economia Regional

Interrup̧̧ão da Navegação no Trecho de Vazão Reduzida nos Períodos de Seca

Perda de ambientes para reprodução, alimentação e abrigo de peixes e outros animais (d)

Formação de poças, mudanças na qualidade das águas e criação de ambientes transmissores doenças

Prejuizos para a pesca e para outras fontes de renda e sustento no Trecho de Vazão Reduzida

FONTE: Adapatado Rima AHE Belo Monte, Eletrobrás, 2009 p.137

(1) Início dos Estudos na ACIA DO Xingu até a obtenção da LP e da LI

(a) Causada pela instalação da infra-estrutura de apoio e das obras principais ; (b) obras no Sitio Pimentel; (c) formação dos reservatórios; (d) trecho de vazão reduzida.

TERCEIRO INCLUÍDO-ISSN 2237-079X - DOI: 10.5216 NUPEAT-IESA-UFG, v.2, n.2, jul./dez., 2012, p. 63-84, Artigo 29
ET A P A S

\begin{tabular}{|l|l|l|l}
\hline ESTUDOS E & IMPLANTACC̃̃O DA INFRA- & ENCHIMENTO & MONTAGEM E TESTE DAS
\end{tabular}

\begin{tabular}{c|c|c|c|} 
ESTUDOS E & ESTRUTURA E DAS OBRAS & $\begin{array}{c}\text { ENCHIMENTO } \\
\text { (30 dias) }\end{array}$ & TURBINAS E GERADORES (5 anos) \\
\cline { 4 - 5 } & &
\end{tabular}

DE ENGENHARIA (5 anos)

OPERAÇÃO COMERCIAL

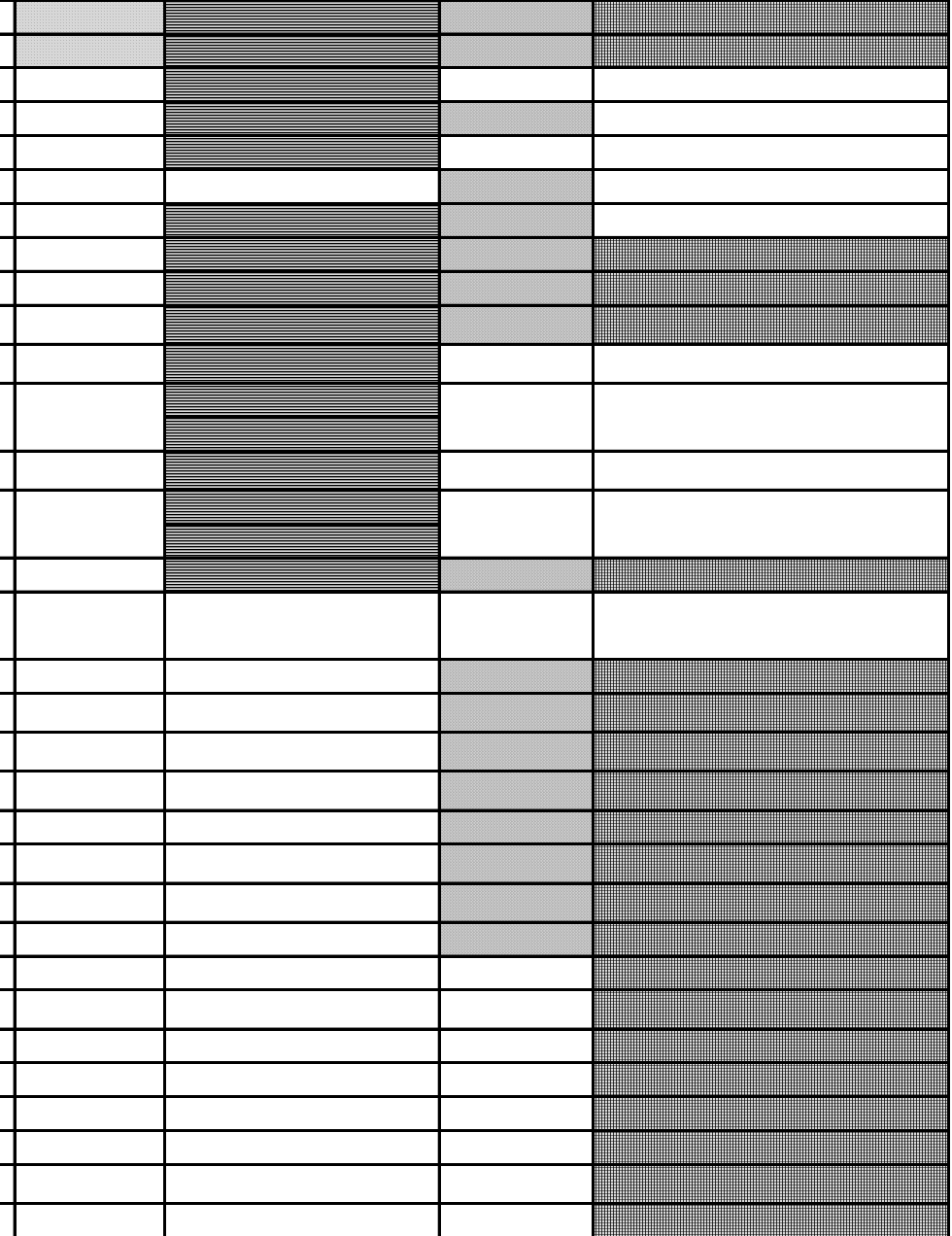


Projetos Integrados de Produção e Escoamento de Petróleo e Gás Natural no Polo Pré-Sal Bacia de Santos

Nesse projeto foram relacionados 26 impactos reais, sendo 20 relativos diretamente ao meio ambiente e 6 referentes ao meio socioeconômico. Deste total, 5 impactos foram classificados como positivos e 21 como negativos. A partir da identificação e classificação desses impactos, o empreendedor propôs medidas preventivas, corretivas, potencializadoras ou compensatórias de acordo com a natureza do dano causado. Os impactos negativos serão tratados com medidas de prevenção, correção ou compensação por meio de projetos como Monitoramento Ambiental (PMA), Controle da Poluição (PCP), Comunicação Social (PCS), Educação Ambiental (PEA) e de Educação Ambiental dos Trabalhadores (PEAT). Aos impactos positivos, medidas incrementais poderão ampliar e melhorar os resultados sobre a atividade (RIMA PETROBRÁS (2011, p. 44)

Para todos os impactos reais identificados, foi proposta pelo RIMA PETROBRÁS (2011) medidas para minimizar/e ou mitigar os problemas abordados, haja vista que a eliminação total do impacto foi descartada. Ações pontuais ou a implantação de programas e projetos específicos objetivam melhorar as condições do meio ambiente afetado, especificamente nos casos onde são classificados como negativos e de alta importância. O Quadro 6 mostra o resumo dos impactos reais apontados pelo RIMA PETROBRÁS (2011).

Os impactos potenciais estão relacionados à ocorrência de acidentes ambientais como vazamento de óleo para o mar, resultando na alteração das condições da água, ar, sedimento, vida marinha e o meio socioeconômico. De acordo com o RIMA PETROBRÁS (2011) procedimentos de segurança e emergência, que tem por objetivo controlar, conter e remover/dispersar o óleo derramado, diminuem as chances da ocorrência de acidentes desta magnitude.

A legislação brasileira exige que o responsável pelo empreendimento simule uma situação de derramamento de óleo para melhor estudar os danos ambientais e sua gravidade. Este procedimento pode ser encarado como uma medida preventiva. Os principais impactos potenciais levantados pelo da RIMA PETROBRÁS (2011) são relacionados nos Quadros 6 e 7. 
Quadro 6 - Identificação de impactos potenciais

\begin{tabular}{|l|c|}
\hline \multicolumn{1}{|c|}{ EFEITO DO DERRAMAMENTO DE ÓLEO } & NÍVEL DO IMPACTO \\
\hline $\begin{array}{l}\text { Liberação de gases tóxicos como Benzeno, nitróxidos etc. } \\
\text { Podem causar efeitos adversos na saúde humana variando } \\
\text { de irritações na garanta a câncer e depressão. }\end{array}$ & $\begin{array}{c}\text { Média importância. } \\
\text { Efeito de curta duração. }\end{array}$ \\
\hline $\begin{array}{l}\text { Aves marinhas podem morrer em contato com o óleo ou } \\
\text { ainda pela ingestão de alimento contaminado. }\end{array}$ & $\begin{array}{c}\text { Em áreas oceânicas não há presença } \\
\text { significativa desses animais }{ }^{1} .\end{array}$ \\
\hline $\begin{array}{l}\text { Os impactos socioeconômicos estão relacionados à perda } \\
\text { do dinamismo turístico. }\end{array}$ & $\begin{array}{c}\text { Alto pela poluição das praias, interrupção da } \\
\text { navegação e da pesca na região. }\end{array}$ \\
\hline
\end{tabular}

FONTE: Adaptado de RIMA PETROBRÁS (2011).

${ }^{1}$ O relatório não traz nenhum dado quantitativo do "grande" em termos de amostra estatística.

Quadro 7 - Identificação de impactos reais

\begin{tabular}{|c|c|c|}
\hline IMPACTO & ESTAPA FASE & LOCAL \\
\hline $\begin{array}{l}\text { Revolvimento da lama no fundo marinho } \\
\text { devido à interferência do navio- } \\
\text { plataforma e/ou sistemas submarinos }{ }^{1} \text {. }\end{array}$ & $\begin{array}{l}\text { Instalação } \\
\text { Desativação }\end{array}$ & $\begin{array}{l}\text { Fundo do mar. } \\
\text { Negativo e de baixa importância. }\end{array}$ \\
\hline $\begin{array}{l}\text { Modificação das comunidades de } \\
\text { organismos que vivem no fundo do mar } \\
\text { devido à interferência do navio plataforma } \\
\text { e/ou sistemas submarinos. }\end{array}$ & $\begin{array}{l}\text { Instalação } \\
\text { Desativação }\end{array}$ & $\begin{array}{c}\text { Fundo do mar. } \\
\text { Negativo e de pequena importância nas } \\
\text { fases de instalação e operação. Alta } \\
\text { importância na fase de desativação. }\end{array}$ \\
\hline $\begin{array}{l}\text { Modificação das comunidades marinhas } \\
\text { pela introdução de novas espécies no } \\
\text { meio ambiente devido à presença do } \\
\text { navio-plataforma e sistemas submarinos. }\end{array}$ & Instalação & $\begin{array}{l}\text { Ambiente marinho. } \\
\text { Negativo de alta importância. }\end{array}$ \\
\hline $\begin{array}{l}\text { Choque de barcos de apoio com baleias e } \\
\text { golfinhos devido à presença do navio- } \\
\text { plataforma e sistemas submarinos. }\end{array}$ & Operação & $\begin{array}{c}\text { Ambiente marinho. } \\
\text { Negativo e de alta importância. }\end{array}$ \\
\hline $\begin{array}{l}\text { Modificação das características da água } \\
\text { do mar devido ao descarte de restos de } \\
\text { comida e efluentes }{ }^{2} \text {. }\end{array}$ & $\begin{array}{l}\text { Instalação } \\
\text { Operação }\end{array}$ & $\begin{array}{l}\text { Proximidades dos navios-plataforma } \\
\text { e barcos de apoio. } \\
\text { Negativo de pouca e média importância. }\end{array}$ \\
\hline $\begin{array}{l}\text { Alteração da qualidade do ar devido a } \\
\text { emissões atmosféricas. }\end{array}$ & Operação & $\begin{array}{c}\text { Proximidades dos navios-plataforma } \\
\text { e barcos de apoio. } \\
\text { Negativo e de alta importância. }\end{array}$ \\
\hline $\begin{array}{l}\text { Interferência de ruídos e de luminosidade } \\
\text { sobre animais marinhos. }\end{array}$ & Operação & $\begin{array}{l}\text { Proximidades dos navios-plataforma. } \\
\text { Negativo e de alta importância. }\end{array}$ \\
\hline $\begin{array}{l}\text { Aumento da demanda sobre as atividades } \\
\text { de comércio e serviços. }\end{array}$ & $\begin{array}{l}\text { Instalação } \\
\text { Operação }\end{array}$ & $\begin{array}{l}\text { Municípios da área de influência. } \\
\text { Positivo de baixa importância. }\end{array}$ \\
\hline $\begin{array}{l}\text { Geração de tributos e incremento das } \\
\text { economias local, estadual e nacional. }\end{array}$ & $\begin{array}{l}\text { Instalação } \\
\text { Operação }\end{array}$ & $\begin{array}{c}\text { Municípios e estados da área } \\
\text { de influência e União } \\
\text { Positivo de baixa importância. } \\
\end{array}$ \\
\hline $\begin{array}{l}\text { Interferência no tráfego marítimo. Aéreo e } \\
\text { rodoviário. }\end{array}$ & $\begin{array}{l}\text { Instalação } \\
\text { Operação }\end{array}$ & $\begin{array}{l}\text { Rotas marítimas das embarcações } \\
\text { de apoio, aérea e rodoviária. } \\
\text { Negativo e de alta importância. }\end{array}$ \\
\hline Pressão sobre a infraestrutura portuária. & $\begin{array}{l}\text { Instalação } \\
\text { Operação }\end{array}$ & $\begin{array}{c}\text { Municípios da área de influência. } \\
\text { Positivo de alta importância. }\end{array}$ \\
\hline Interferência com atividades pesqueiras. & $\begin{array}{l}\text { Instalação } \\
\text { operação }\end{array}$ & $\begin{array}{c}\text { Zona de } 500 \mathrm{~m} \text { ao redor dos FPSO } \\
\text { e rota marítima das embarcações de apoio. } \\
\text { Negativo e de baixa importância. }\end{array}$ \\
\hline $\begin{array}{l}\text { Pressão sobre a infraestrutura de } \\
\text { disposição final de resíduos. }\end{array}$ & $\begin{array}{l}\text { Instalação } \\
\text { Operação }\end{array}$ & $\begin{array}{l}\text { Municípios da área de influência. } \\
\text { Negativo de baixa importância. }\end{array}$ \\
\hline
\end{tabular}

FONTE: Adaptado de RIMA PETROBRÁS (2011).

${ }^{1}$ Sistemas submarinos: equipamentos e estruturas que ficam dentro do mar durante o empreendimento.

${ }^{2}$ Efluente: líquidos descartados como esgoto doméstico. 
Adicionalmente a Petrobrás dispõe de um trabalho específico de análise de riscos de potenciais vazamentos de óleo para o qual conta com respectivo Plano de Emergência para esse caso e Planos de Emergência Individual para as atividades da Bacia de Santos. O objetivo desse trabalho é avaliar em toda a sua potencialidade essas situações, para melhor orientar os trabalhadores no combate de um possível vazamento de óleo. São definidas as "responsabilidades e atribuições das equipes destinadas a atuar nas respostas à emergência e os procedimentos a serem adotados em cada situação" (RIMA PETROBRÁS, 2011 p.52-53).

\section{Unidade Industrial da Brazil Flex Energy}

Atividade sucroalcooleira tem despertado o interesse de investidores interessados em diversificar e ampliar suas fontes de lucro. Foram identificados 28 tipos de impactos ambientais de diferentes magnitudes e abrangência neste projeto, dos quais 22 são negativos e 6 positivos. Em resposta a pressão exercida sobre o meio a empresa propõe um rol de programas ambientais em compatibilidade com as áreas protegidas por Lei. De acordo com o RIMA da Brasil Flex Energy "as atividades serão desenvolvidas em conformidade com as diretrizes dos planos de manejo das Unidades de Conservação Estação Ecológica Mico-Leão-Preto e Parque Estadual do Morro do Diabo" (RIMA BRASIL FLEX ENERGY, 2011 p. 65). Estes programas integrarão parte do Sistema de Gestão Ambiental (SGA) da usina. O Quadro 8 mostra os principais impactos ambientais apontados no projeto de implantação da usina para produção de cana-de-açúcar.

Quadro 9 - Identificação de impactos ambientais

\begin{tabular}{|l|l|}
\hline \multicolumn{1}{|c|}{ DESCRIÇÃO DO IMPACTO } & \multicolumn{1}{|c|}{ NíVEL DO IMPACTO } \\
\hline $\begin{array}{l}\text { Alteração da paisagem local em razão das obras de } \\
\text { implantação do parque industrial. }\end{array}$ & $\begin{array}{l}\text { Impacto negativo, abrangência local, } \\
\text { reversível, alta magnitude e permanente. }\end{array}$ \\
\hline $\begin{array}{l}\text { Supressão de vegetação nativa em função da implantação } \\
\text { das lavouras de cana-de-açúcar. }\end{array}$ & $\begin{array}{l}\text { Impacto negativo, abrangência local, } \\
\text { temporário, reversível e média magnitude. }\end{array}$ \\
\hline $\begin{array}{l}\text { Contaminação ambiental pela aplicação de maturadores por } \\
\text { via aérea. }\end{array}$ & $\begin{array}{l}\text { Impacto negativo, abrangência local, } \\
\text { reversível, temporário de média } \\
\text { magnitude. }\end{array}$ \\
\hline $\begin{array}{l}\text { Alteração da matriz ambiental decorrente da implantação } \\
\text { dos canaviais. }\end{array}$ & $\begin{array}{l}\text { Impacto negativo, abrangência local, } \\
\text { reversível, de média magnitude } \\
\text { temporário. }\end{array}$ \\
\hline $\begin{array}{l}\text { Contaminação do solo por resíduos decorrentes da operação } \\
\text { industrial. }\end{array}$ & $\begin{array}{l}\text { Impacto negativo, abrangência local, } \\
\text { reversível, grande magnitude e } \\
\text { temporário. }\end{array}$ \\
\hline Acidentes em função da estocagem de etanol. & $\begin{array}{l}\text { Impacto negativo, abrangência local, } \\
\text { irreversível, temporário e de grande } \\
\text { intensidade. }\end{array}$ \\
\hline $\begin{array}{l}\text { Migração e pressão sobre os equipamentos e serviços } \\
\text { públicos. }\end{array}$ & $\begin{array}{l}\text { Impacto negativo, abrangência local, } \\
\text { caráter reversível, grande magnitude e } \\
\text { tendência de crescimento. }\end{array}$ \\
\hline
\end{tabular}

FONTE: Adaptado de RIMA BRAZIL FLEX (2011). 


\section{DISCUSSÃO}

O Quadro 10 mostra um comparativo entre variáveis que influem na opção de investimento das diferentes fontes de energia. Foram considerados os impactos reais e potenciais. Considera-se impactos potenciais aqueles que podem ocorrer em casos de acidentes de derramamento de óleos ou produtos químicos.

Observa-se o menor custo de geração a partir da fonte hidráulica, seguido do baixo custo do petróleo e seus derivados. Com respeito as hidrelétricas, o ponto favorável é a geração de energia renovável e barata, entretanto esses projetos demandam altos investimentos que recaem praticamente sobre o Estado. O potencial de mercado do etanol tem atraído investidores, além disso, o açúcar mostrou-se competitivo no mercado internacional em 2011.

Quadro 10 - Comparativo entre os projetos a partir de seus EIA/RIMA

\begin{tabular}{|c|c|c|c|}
\hline $\begin{array}{c}\text { ITEM } \\
\text { (Projeto) }\end{array}$ & $\begin{array}{c}\text { UHE } \\
\text { BELO MONTE }\end{array}$ & $\begin{array}{c}\text { PRÉ-SAL } \\
\text { BACIA SANTOS }\end{array}$ & $\begin{array}{l}\text { BRASIL FLEX } \\
\text { ENERGY }\end{array}$ \\
\hline $\begin{array}{l}\text { Investimento } \\
\text { Estimado }\end{array}$ & $\begin{array}{l}\mathrm{R} \$ 20,3 \text { bilhões } \\
\text { (ano de ref. 2008) }\end{array}$ & $\begin{array}{l}\text { Informação } \\
\text { Indisponível }\end{array}$ & $\mathrm{R} \$ 120.000 .000$ \\
\hline $\begin{array}{l}\text { Custo geração } \\
\text { por fonte } \\
(\mathrm{kW})\end{array}$ & $\begin{array}{c}\text { Hidrelétricas }{ }^{(1)} \\
\text { US\$ } 1.330 \\
\text { Ou R\$ 77,97 MWh }\end{array}$ & $\begin{array}{c}\text { Térmicas a gás } \\
\text { natural } \\
\text { US\$ } 750\end{array}$ & $\begin{array}{c}\text { Co-geração a partir } \\
\text { da cana } \\
\text { US\$ } 900\end{array}$ \\
\hline $\begin{array}{l}\text { Retorno } \\
\text { Esperado }\end{array}$ & $\begin{array}{c}+11.233 \mathrm{MW} \\
\text { na matriz elétrica brasileira }\end{array}$ & $\begin{array}{c}+1,35 \% \text { acréscimo } \\
\text { a produção } \\
\text { nacional de } \\
\text { petróleo e gás }\end{array}$ & $\begin{array}{c}3 \text { milhões ton de cana-de- } \\
\text { açúcar/safra } \\
105 \text { mil ton açúcar } \\
124,5 \text { mil m3 etanol } \\
295,5 \mathrm{MW} \text { de } \\
\text { energia elétrica } \\
\text { 31\% consumo próprio }\end{array}$ \\
\hline $\begin{array}{l}\text { № Impactos } \\
\text { Socioamb. } \\
\text { Totais }\end{array}$ & $\begin{array}{c}35 \text { impactos socioambientais } \\
4 \text { positivos }\end{array}$ & $\begin{array}{l}26 \text { impactos } \\
5 \text { positivos }\end{array}$ & $\begin{array}{l}28 \text { impactos } \\
6 \text { positivos }\end{array}$ \\
\hline $\begin{array}{l}\text { Investimento } \\
\text { em } \\
\text { Mitigação de } \\
\text { Impactos }\end{array}$ & $\begin{array}{c}\text { Cerca de R\$ 3,7 bilhões em ações } \\
\text { socioambientais, R\$ } 500 \text { milhões do } \\
\text { Plano de Desenvolvimento Regional } \\
\text { Xingu (PDRS) e R\$ 3,2 bilhões do } \\
\text { Plano Básico Ambiental (realocação } \\
\text { de comunidades e fomento de } \\
\text { economia local, preservação de fauna } \\
\text { e flora, etc.). } \\
\text { Considerar a compensação ambiental } \\
\text { para os municípios atingido ver } \\
\text { EIA/RIMA, p. } 127\end{array}$ & $\begin{array}{l}\text { Informação } \\
\text { Indisponível }\end{array}$ & $\begin{array}{c}\text { Art. } 36 \text { Lei no 9.985/00 } \\
\text { Valor estimado para } \\
\text { compensação ambiental } \\
\text { R\$ 1.141.791,72 } \\
\text { Parque Estadual do Morro } \\
\text { do Diabo e Estação } \\
\text { Ecológica Mico-Leão-Preto }\end{array}$ \\
\hline
\end{tabular}

FONTE: Dados Brutos de EIA/RIMA UHE BELO MONTE (2009); EIA/RIMA BACIA DE SANTOS (2011); EIA/RIMA BRASIL FLEX ENERGY (2011); TOLMASQUIM (2007); VENTURA FILHO (2011), 
O Quadro 11 mostra os principais impactos ambientais/socioeconômicos de cada projeto a partir de seus EIA/RIMA. Para os três projetos analisados verificaram-se externalidades positivas que se tratadas adequadamente podem trazer benefícios, na geração de oportunidades de postos de trabalho diretos ou indiretos e a expansão da oferta de produtos e serviços que podem dinamizar a economia local.

No tocante aos aspectos positivos, no caso do projeto da Brasil Flex Energy, destaca-se que o aumento das receitas municipais e estaduais poderá incrementar a circulação de capital para o setor sucroenergético resultando em desenvolvimento da região, bem como o potencial de geração de 1.885 postos de trabalho. No caso do pré-sal destacou-se a dinamização do comércio local e a importância dos TDL's na geração de um banco de informações sobre a capacidade dos reservatórios e comportamento da produção futura. Os municípios de Maricá, Itaguaí e Mangaratiba (RJ) e Ilhabela (SP) foram definidos como os possíveis beneficiários dos royalties gerados pela atividade.

Com respeito as influências negativas, no caso da Bacia de Santos, o estudo demonstrou que os impactos diretos sobre o meio ambiente, em sua maioria estão concentrados em áreas oceânicas, afetando as populações marinhas e alterando as condições gerais da água. Acidentes não são descartados, porém, planos para mitigá-los estão previstos na estratégia da Petrobrás e são de prioridade alta. Riscos de vazamento de óleo foram identificados, analisados e contemplados com medidas de controle de acordo com o RIMA.

A maior carga de impactos ambientais diretos do projeto da usina de cana-de-açúcar recai sobre o componente físico terrestre que demandarão formas adequadas de manejo do solo. Serão erradicadas populações arbóreas isoladas o que demandará reposição conforme previsto na legislação. A demanda hídrica também pressionará os recursos aquíferos, mas a empresa estima um consumo controlado de água na ordem de $0,44 \mathrm{~m}^{3} /$ tonelada/cana moída (RIMA BRASIL FLEX ENERGY, 2010). Quanto ao gerenciamento de resíduos, a empresa necessariamente deverá atender a norma ABNT NBR 10.004/04 que prevê ações de redução de resíduos de aterros, reciclagem e destino adequado os resíduos gerados no processo industrial. $\mathrm{O}$ armazenamento de etanol configura-se um risco de alto impacto por ser produto inflamável.

O EIA/RIMA da UHE de Belo Monte expôs 35 impactos ambientais, entretanto, não apresentou classificação em termos de magnitude e abrangência. São 4 impactos positivos relacionados a dinamização da economia local, geração de empregos e oportunidades de trabalho indiretos. Os impactos negativos mais expressivos dizem respeito a áreas de alagamento, 
comprometimento da fauna e flora, aumento da demanda de energia pelo desenvolvimento do empreendimento e prejuízos para a pesca local. Haverá perda de patrimônio arqueológico e ressaltase o aumento da pressão sobre as terras e áreas indígenas. Vale destacar que Licença Prévia estabeleceu 40 condicionantes que visam a prevenção, mitigação ou compensação dos impactos prevista no EIA (EPE, 2011 p.2).

Quadro 11 - Comparativo dos impactos ambientais/socioeconômicos de cada projeto a partir de seus EIA/RIMA

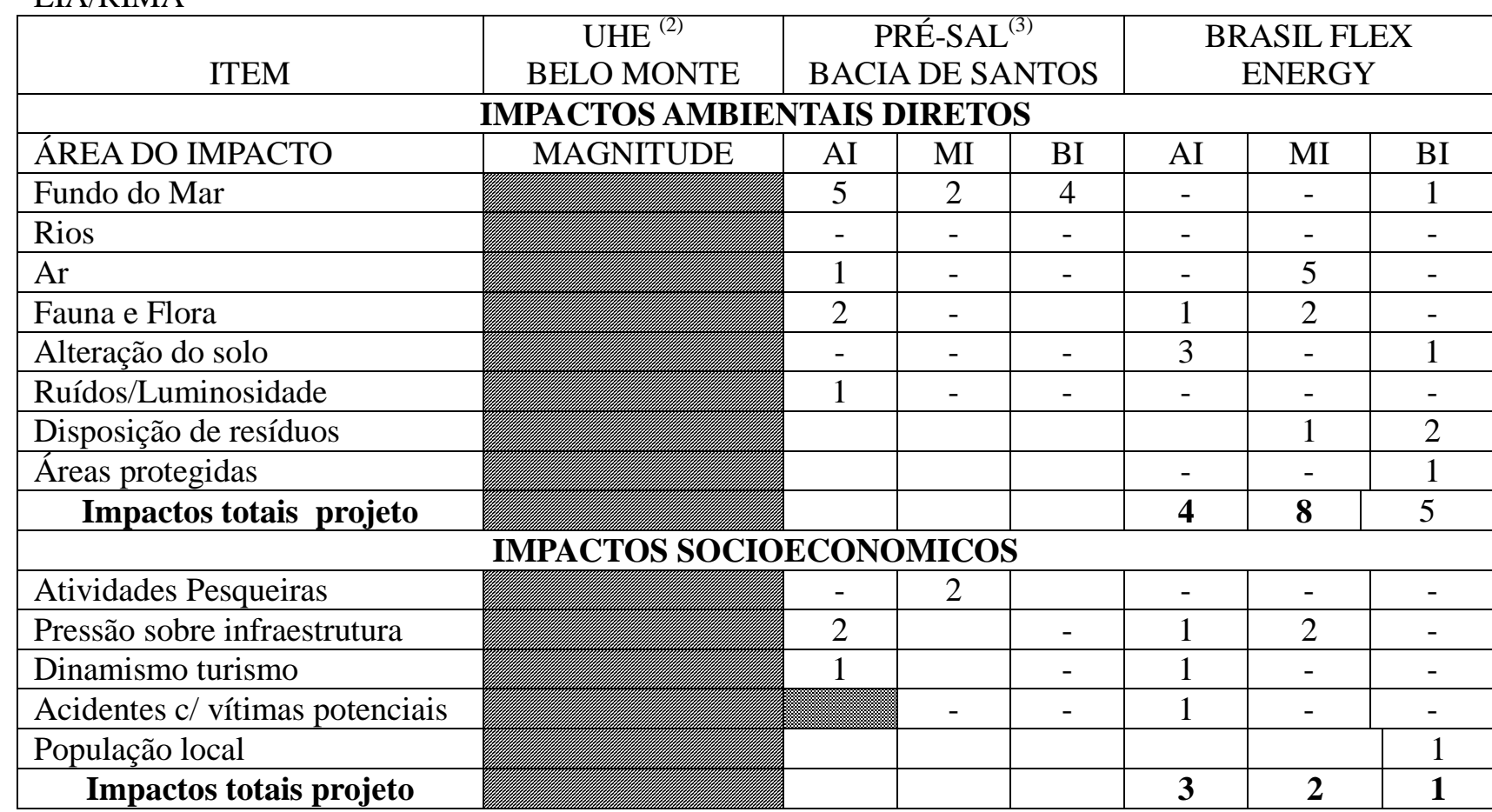

FONTE: Dados Brutos de EIA/RIMA UHE BELO MONTE (2009); EIA/RIMA BACIA DE SANTOS (2011); EIA/RIMA BRASIL FLEX ENERGY (2011)

${ }^{(1)} \mathrm{AI}=$ Alto Impacto; MI Médio Impacto; BI = Baixo Impacto.

${ }^{(2)}$ O EIA/RIMA de Belo Monte não adotou a classificação de alto, médio e baixo impacto em seu relatório.

${ }^{(3)}$ Os acidentes com vítimas potenciais no caso da Bacia de Santos referem-se a impactos potenciais.

\section{CONSIDERAÇÕES}

Do homem pré-histórico que usou os recursos naturais para sua subsistência, às sociedades industriais do século XXI, não há atividade humana livre de impactos ambientais. O custo de oportunidade do progresso e da modernidade, ao longo dos séculos se materializou em problemas de degradação ambiental e disfunções de natureza social como a ampliação das desigualdades agravamento da pobreza e violência nos países subdesenvolvidos, mas essa discussão tem sido tratada com maior seriedade somente a partir de meados da década de 1970 quando os primeiros documentos denunciaram os perversos efeitos da modernidade. 
O Brasil, ao contrário da maioria dos países desenvolvidos, utiliza parcela expressiva de fontes renováveis de energia, e tem buscado amadurecer no seu Planejamento de Expansão de Energia a diversificação dessas fontes. Contudo, o ciclo de expansão econômico requer ampliação da infraestrutura energética, e para tanto, o governo tem lançado mão da construção de hidrelétricas, enquanto a iniciativa privada tem aproveitado as oportunidades do mercado de etanol. Tais fontes se mostram economicamente mais baratas e na perspectiva ambiental apresentam menores danos pela sua utilização, entretanto, ainda se mostram caras para o mercado brasileiro e faltam políticas públicas para melhor desenvolver esta potencialidade.

No caso da UHE Belo Monte, o empreendimento tem recebido fortes pressões por parte de ambientalistas e de grupos que defendem os interesses indígenas. As hidrelétricas indicam tendência de perda de participação na matriz energética à medida que a biomassa e outras fontes como a eólica se apresentam mais competitivas e de maior densidade energética. O Brasil detém 10\% do potencial hidráulico técnico mundial (TOLMASQUIM, 2012 p.252), e, dentre as opções renováveis, pode-se considerá-la a menos poluente, satisfatoriamente competitiva, geradora de empregos e renda. Vale destacar que os impactos relacionados no EIA/RIMA desse empreendimento mostram-se localizados em contraste com as centrais térmicas.

Chamou a atenção o crescimento da energia de fonte eólica que variou positivamente $24 \%$ em relação a 2010 (BEN, 2012). Vale destacar que o custo de geração da energia eólica em 2011 foi na média R \$ 105,00 MWh, 1/3 inferior aos valores de 2005 que estavam por volta de R \$300,00 MWh (EPE,2012). Esse comportamento mostra o potencial dessa fonte e a oportunidade de diversificação da matriz energética, não desconsiderando o seu caráter de complementaridade, haja vista, a impossibilidade de armazenamento desse recurso e a incerteza da garantia de energia firme.

Em relação ao Pré-Sal da Bacia de Santos, os impactos restringem-se a área de afluência, mas deve-se considerar a importância da atividade de Testes de Longa Duração- TDL's, que contribuem para evitar a geração de mais testes, anteriormente a fase de extração do petróleo. São conhecidos os riscos e impactos das atividades de prospecção e exploração dessa fonte de energia, entretanto, sob a perspectiva econômica, esse risco é assumido como inerente a atividade. Igualmente são conhecidos os benefícios de uma balança comercial favorável ao país no caso do petróleo efetivarse como um negócio para o mercado externo.

Os resultados da pesquisa indicaram que os recursos renováveis, no caso brasileiro especialmente o potencial hidráulico, apontam impactos socioambientais que devem ser monitorados e reavaliados no intuito de melhor estabelecer os cenários futuros do desenvolvimento sustentável. 
Destaca-se a importância do etanol e da energia eólica no horizonte de planejamento até 2020 em substituição gradativa a geração de energia elétrica de fonte hidráulica e os rumos dos campos de petróleo do pré-sal. Segundo o Plano de Negócios 2011-2015 da PETROBRÁS “a participação do Pré-sal na produção de petróleo passará dos atuais 2\% para 18\% em 2015 e para 40,5\% em 2020" reforçando a importância dessa fonte sob a perspectiva.

Entende-se que algumas mudanças só acontecerão no longo prazo, especialmente aquelas relacionadas aos padrões de consumo e forma de exploração dos recursos produtivos. Também parece provável que outras não ocorrerão em detrimento da forte relação com o capital privado e possíveis alterações dos resultados financeiros das empresas. Diante desse quadro, espera-se que as pesquisas avancem na busca de uma solução que equilibre as relações entre capital, meio ambiente e os anseios da sociedade.

\section{REFERÊNCIAS BIBLIOGRÁFICAS}

ANP - Agência Nacional do Petróleo. ANP apresenta regulação brasileira e oportunidades de investimento na OTC-2012. $\quad$ Disponível em <http://anp.gov.br/?pg=60260\&m=\&t1=\&t2=\&t3=\&t4=\&ar=\&ps=\&cachebust $=1339033498165>$ Acesso em: jan. 2012.

BALANÇO PAC 2010. Décimo balanço dos investimentos previstos no Programa de Aceleração do Crescimento - PAC. Disponível em < http://www.brasil.gov.br/pac/relatorios/nacionais/10o-balanco/parte-6-habitacao> Acesso em: jun. 2012.

BEN - Balanço Energético Nacional (2012). Dados Preliminares. Disponível em <https://ben.epe.gov.br/ > Acesso em: abr. 2012.

BEN - Balanço Energético Nacional (2010). Disponível em <https://ben.epe.gov.br/ > Acesso em: abr. 2012.

BIG - Banco de Informações de Geração. Disponível em <http://www.aneel.gov.br/15.htm> Acesso em: jun. 2012.

ELETROBRÁS - Centrais Elétricas Brasileiras S.A. Informativo eletrônico: AHE Belo Monte. Edição 11, Março-Abril 2009. Disponível em: <www.eletrobras.com/.../ContentManagementPlus/FileDownload.ThrS...> Acesso em: jun. 2012.

EPE - Empresa de Pesquisa Energética. Aspectos fundamentais de planejamento energético (Dezembro 2005). Disponível em:

<http://www.sudene.gov.br/conteudo/download/PE_Aspectos_Fundamentais.pdf Acesso em: jun. 2012.

EPE - Empresa de Pesquisa Energética. Projeto da Usina Hidrelétrica de Belo Monte Fatos e
Dados.
Disponível
em 
http://www.epe.gov.br/leiloes/Paginas/Leil\%C3\%A3o\%20UHE\%20Belo\%20Monte/EPEdisponibili zaFatoseDadosePerguntasFrequentessobreBeloMonte.aspx - > Acesso em: jun. de 2011.

MACHADO, Paulo Afonso Leme. Direito ambiental brasileiro. $5^{\text {a }}$ ed. São Paulo: Malheiros Editores, 1995.

MMA - MINISTÉRIO DE MINAS E ENERGIA. RESOLUÇÃO CONAMA No 001, de 23 de janeiro de 1986. Publicado no Diário Oficial da União de 17/02/86. Disponível em < http://www.mma.gov.br/port/conama/res/res86/res0186.html> Acesso em: jun. 2012.

NOGUEIRA PINTO, Fabiano Augusto Castro. Défict energético. Revista Análise Econômica (Faculdade de Ciências Econômicas da UFRGS) Ano 8 № 14 Novembro de 1990 p.69-75.

NORTE ENERGIA. Projeto Básico Ambiental. Versão Final, Set/2011. Volume I 1 Caracterização. Disponível em < http://norteenergiasa.com.br/site/categoria/documentos/zz-projetobasico-ambiental/ > Acesso em: jun. 2012.

PDEE - PLANEJAMENTO DECENAL DE EXPANSÃO DE ENERGIA 2020 Disponível em < http://www.epe.gov.br/PDEE/Forms/EPEEstudo.aspx> Acesso em: mai. 2012.

Petrobrás - Descobrimos petróleo leve na Bacia de Santos. Disponível em < http://www.petrobras.com.br/pt/noticias/descobrimos-petroleo-leve-na-bacia-de-santos/ > Acesso em: jun. 2012.

PLANALTO. Disponível em <http://www.planalto.gov.br/ccivil_03/leis/L6803.htm> Acesso em: jun. 2012.

REIS, Lineu Belico dos; FADIGAS, Eliane Aparecida Faria Amaral; CARVALHO, Claudio Elias. Energia, recursos naturais e a prática do desenvolvimento sustentável. 2.ed. ver. e atual. Barueri: Manole, 2012.

RIMA BRASIL FLEX ENERGY. Dezembro de 2010. Disponível em <http://www.comitepp.sp.gov.br/popup.html > Acesso em: mai. 2012.

RIMA PETROBRÁS - Projetos Integrados de Produção e Escoamento de Petróleo e Gás Natural no Polo Pré-Sal, Bacia de Santos. Revisão 2 Março de 2011. Disponível em < siscom.ibama.gov >

Acesso em: mai. 2012.

RIMA USINA HIDRELÉTRICA DE BELO MONTE. Versão 2009. Disponível em < http://www.eletrobras.com/elb/main.asp?View=\%7B46763BB8-3B05-432F-A206-

C8F93CC3BA90\%7D> Acesso em: mai. 2012.

ROCHA, Ednaldo Candido; CANTO, Juliana Lorensi de; PEREIRA, Pollyana Cardoso. Avaliação de impactos ambientais nos países do Mercosul. Disponível em: <http://www.scielo.br/pdf/asoc/v8n2/28609.pdf> Acesso em: jun. 2012.

TOLMASQUIM, Mauricio Tiommo; GUERREIRO, Amilcar; GORINI, Ricardo. Matriz energética brasileira. Novos Estudos CEBRAP № 79 Novembro de 2007 pp. 47-69.

VENTURA FILHO, Altino. O empreendimento de Belo Monte e o Planejamento e a Expansão do Sistema Elétrico Brasileiro. Ministério de Minas e Energia. Brasília, 17/05/2011. Disponível em < www.blogbelomonte.com.br/Apresentação_MME_BeloMonte.ppt> Acesso em: abr. 2012.

VERGARA, Sylvia Constant. Projetos e relatórios de pesquisa em administração. 3.ed. São Paulo: Atlas, 2000. 